\title{
Population and Housing Census Articles in earlier Volumes of the Journal
}

Relevant Population and Housing Census articles in earlier Volumes of the Statistical Journal of the IAOS (2007-2019) and the Statistical Journal of the United Nations Economic Commission for Europe (19952006).

\section{Statistical Journal of the IAOS (2007-2019)}

Argüeso, Antonio and Vega, Jorge L. 'A Population Census Based on Registers and a "10\% Survey" Methodological Challenges and Conclusions'. 2014: 35-39.

Baffour, Bernard et al. 'Small Area Estimation Strategy for the 2011 Census in England and Wales'. 2018: 395-407.

Baffour, Bernard, Brown, James J., and Smith, Peter W.F. 'An Investigation of Triple System Estimators in Censuses'. 2013: 53-68.

Baffour, Bernard and Valente, Paolo. 'An Evaluation of Census Quality'. 2012: 121-135.

Beltadze, Diana. 'Enumeration via Internet - Estonian Experience'. 2016: 563-568.

Blumerman, Lisa M., Bishop, Deirdre Dalpiaz, and Dinwiddie, James L. 'Plans and Innovations for the 2020 Decennial Census of the United States 1'. 2016: 159-166.

Bourezgue, Tarik. 'Using Tablets for the 2018 Algerian Census: Census Data Management and Quality Assessment'. 2017: 777-784.

Brown, James J. et al. 'The Framework for Estimating Coverage in the 2011 Census of England and Wales: Combining Dual-system Estimation with Ratio Estimation'. 2019: 481-499.

Bycroft, Christine. 'Census Transformation in New Zealand: Using Administrative Data Without a Population Register'. 2015: 401-411.

Chow, Melissa C. et al. 'Hard to Count: How Survey and Administrative Records Modeling Can Enhance Census Nonresponse Followup'. 2018: 505-511. da Silva, Andréa Diniz, de Freitas, Marcos Paulo Soares, and Pessoa, Djalma Galvão Carneiro. 'Assessing Coverage of the 2010 Brazilian Census'. 2015: 215-225.

de Oliveira Martins Pereira, Nilza. 'Innovations on Measuring the Indigenous Population in the 2010 Brazilian Population Census'. 2017: 487-494.

Dolenc, Danilo. 'Novelties of the 2002 Census in Slovenia: The Use of the Combined Method and Outsourcing of Census Operations'. 2007: 111-119. Print.

Dunne, John. 'The Irish Statistical System and the Emerging Census Opportunity’. 2015: 391-400.

Dunne, John and MacFeely, Steve. 'Laying the Foundations for a New Approach to Census Taking in Ireland'. 2014: 359-365.

Fleishman, Larisa and Gubman, Yury. 'Mass Appraisal at the Census Level: Israeli Case'. 2015: 597612.

Juran, Sabrina and Pistiner, Arona L. 'The 2010 Round of Population and Housing Censuses (20052014) 1'. 2017: 399-406.

Juran, Sabrina and Snow, Rachel C. 'The Potential of Population and Housing Censuses for International Migrant Analysis'. 2018: 203-213.

Keller, Andrew. 'Imputation Research for the 2020 Census 1'. 2016: 189-198.

Keita, Naman and Gennari, Pietro. 'Building a Master Sampling Frame by Linking the Population and Housing Census with the Agricultural Census'. 2014: 21-27.

Kissam, Edward. 'Differential Undercount of Mexican Immigrant Families in the U.S. Census'. 2017: 797-816.

—. 'How Low Response Among Latino Immigrants Will Lead to Differential Undercount If the United States' 2020 Census Includes a Question on Sensitive Citizenship'. 2019: 221-243.

Konicki, Scott and Adams, Tamara. 'Adaptive Design Research for the 2020 Census 1'. 2016: 167-176. 
Lagarto, Sandra et al. 'When Is Administrative Data Good Enough to Replace Statistical Information? A Quality Indicator Based on Census Comparison'. 2017: 749-753.

Lange, Anita. 'The Population and Housing Census in a Register Based Statistical System'. 2014: 41-45.

Marciniak, Grażyna. 'Modern Approach to Censuses in the Case of Poland - Advantages and Constraints'. 2014: 29-34.

Morris, Darcy Steeg, Keller, Andrew, and Clark, Brian. 'An Approach for Using Administrative Records to Reduce Contacts in the 2020 Decennial Census'. 2016: 177-188.

Nordholt, Eric Schulte and Linder, Frank. 'Record Matching for Census Purposes in the Netherlands'. 2007: 163-171. Print.

O’Hare, William P. 'An International Perspective on the Undercount of Young Children in the U.S. Census'. 2017: 289-304.

Ramachandran, Ramasamy. 'Augmenting Census and Sample Records for Estimating Information Communications Technology (ICT) Penetration Rates at the Lowest Administrative Level Using an Interdisciplinary Approach'. 2017: 637-644.

Schulte Nordholt, Eric. 'The Usability of Administrative Data for Register-based Censuses'. 2018: 487498.

Thygesen, Lars. 'The Use of Administrative Sources for Censuses: Merits and Challenges'. 2015: 381-389.

Toulemon, Laurent. 'Undercount of Young Children and Young Adults in the New French Census'. 2017: 311-316.

Williams, Paul. 'The Australian 2006 Census and the Internet'. 2007: 173-182. Print.

\section{Statistical Journal of the United Nations Economic Commission for Europe (1998-2006)}

Al Raisi, Ali Mahboob Hassan. 'The Use of Handheld Devices and Other Modern Technologies in the 2003 Census of the Sultanate of Oman'. 2005: 73-89.
Carter, Richard and McClean, Kathy. 'Using Administrative Data in the Canadian Census: Experiences and Plans'. 1996: 375-383.

Durr, Jean-Michel. 'The French New Rolling Census'. 2005: 3-12.

Griffin, Tom. 'The Census in Europe'. 1999: 223 230.

Harala, Riitta. 'Evaluation of the Results of the Register-based Population and Housing Census 1990 in Finland'. 1995: 63-72.

Kamen, Charles S. 'The 2008 Israel Integrated Census of Population and Housing'. 2005: 39-57.

Kelly, John and Mikkelsen, Lene. 'Focus on the Recommendations for the 2000 Censuses of Population and Housing in the ECE Region'. 1998: 177-178.

Kolesnikov, Sergei. 'All-russia Population Census - 2002: Information, Communications, Public Relations'. 2003: 235-240.

Máté, Ian and Miller, Gillian. 'The UK 2001 Census Question on Within Household Relationships'. 2003: 27-37.

Myrskyla, Pekka. 'New Statistics Made Possible by the Use of Registers'. 1999: 165-180.

Nordholt, Eric Schulte. 'The Dutch Virtual Census 2001: A New Approach by Combining Different Sources'. 2005: 25-37.

Punch, Aidan. 'The 2000 Round of Censuses - A Review of Major Issues'. 1999: 207-221.

Szenzenstein, Johann. 'The New Method of the Next German Population Census'. 2005: 59-71.

Waite, Preston Jay and Reist, Burton H. 'Reengineering the Census of Population and Housing in the United States'. 2005: 13-23. 